\title{
Specific odor component produced by Mycobacterium lepraemurium on Ogawa yolk medium.
}

\author{
${ }^{1}$ Tatsuo Mori and ${ }^{2}$ Tetsuo Aishima \\ ( ${ }^{1}$ National Institute for Leprosy Research, ${ }^{2}$ Kikkomann Corp, R \& D) \\ (Received for publication: June12,1992)
}

Key Words : $M$. lepraemurium, odor component, phenyl acetic acid

When Mycobacterium lepraemurium is grown on the $1 \%$ Ogawa yolk medium, it produces a specific odor. This odor was not observed in other easily cultivable acid-fast bacilli. Therefore, identification of the components responsible for the specific odor produced by $M$. lepraemurium was attempted.

The odor components were extracted for overnight with sterilized and distilled water from the Ogawa yolk medium on which $M$. lepraemurium had been cultivated for two months. The odor components in the extract was adsorbed on refined char. coal. After washing with distilled water for three times, the charcoal was dried. Then the odor components were eluted from the charcoal with ethanol and the eluate was condensed under nitrogen gas flow at $40^{\circ} \mathrm{C}$. The condensate was analyzed by Gas Chromatography-Mass-Spectrum (GC.MS). Phenylethanol and phenylacetic acid were identified as major odor components. A mixture of authentic phenylacetic acid, its methyl and ethylesters, smelled similar to the odor of cultivated medium of $M$. lepraemurium. Thus, phenylacetic acid was identified as the key odor component produced by M. lepraemurium.

When initial isolation culture of $M$. lepraemurium from murine leproma was cultivated on the Ogawa yolk medium by adding phenylacetic acid, growth inhibition was brought by the compound.

\section{小川卵黄培地に増殖したネズミライ菌の 産生する特徵香成分について}

\author{
${ }^{1}$ 森 龍 男 ${ }^{2}$ 相 島 鐵 郎 \\ '元国立多摩研究所 ${ }^{2}$ キッコーマン研究本部 \\ キーワード：ネズミライ菌，香成分， phenylacetic acid
}

\section{実験方法}

1 特徵香成分の抽出：ネズミライ菌の增殖した 小川卵黄培地 (通常 2 ヶ月培養)に滅菌蒸留水 $5 \mathrm{ml}$ を加元斜保って保っ夜放置後，この抽出液を濾 紙を用いて滤過した。滤液を12000rpmで20分間 遠心して除菌，その上澄液約11を得た。濃塩酸と 濃硝酸により洗浄後, 蒸留水で十分洗浄し,
燐酸緩衝液でpH6.1に調整した精製活性炭 $2 \mathrm{~g}$ を 上記上澄液に加え十分攪找後, 濾過した。匂い成 分を吸着した活性炭を蒸留水により 3 回濾過洗浄 後, $42^{\circ} \mathrm{C}$ で乾燥した。乾燥した活性炭から工夕ノー ルにより包い成分を溶出した。エ夕ノール抽出液 は乾燥窒素気流により $40^{\circ} \mathrm{C} て ゙$ 濃縮した。

2 匂い成分の分析：GC-MS分析はガスクロマ 
トグラフHP5980A と直結したHP5971A質量分析 計 (Hewlett-Pack ard Co. , Palo Alto, CA) によ り行った。カラムは DB - WAX (crosslinked polyethylene glycol, J\& W Scientific, Inc. , Rancho Cordova, CA）を液層膜厚 $0.25 \mu \mathrm{m}$ に塗布し た長さ $30 \mathrm{~m}$, 内径 $0.25 \mathrm{~mm}$ のューズドシリカキャ ピラリーカラムを用いた。キャリアガスはHeを 用い流速を $1 \mathrm{ml} /$ 分に設定した。試料は1 1 亿を 注入し,スプリットレス (purge ontime：0.75分) モードで分析した。注入口温度 $230^{\circ} \mathrm{C}$, 初期温度 $50^{\circ} \mathrm{C}$, 昇温速度 $8^{\circ} \mathrm{C} /$ 分で $220^{\circ} \mathrm{C}$ まで昇温しそのま ま25分間保った。質量分析はイオン化電圧 $70 \mathrm{eV}$ のEIモードでイオン化，質量範囲35-400amuを 1.5/秒でスキャンした。各ピークのマススペクト ルとデータベース中の標準スペクトルとの比較に より包い成分を同定した。

3 phenylacetic acid $の$ 生物学的作用：段階的に 異なる濃度のphenylacetic acidを滅菌した1\%小 川㥜黄培地の基礎培地に加え, pHを5.1亿調整し て卵黄培地を作成した。すなわち培養には $1 \%$ 小 川卵黄培地老対照とし， $1 \mathrm{mM} / \mathrm{ml}, 3.3 \mathrm{mM} / \mathrm{ml}$, $10 \mathrm{mM} / \mathrm{ml}$ phenylacetic acidを含む 3 種類の $1 \%$ 小 川邲黄培地を用いた。接種材料としては(1) $1 \mathrm{~g} の$ ネズミライ結節を磨砕し乾燥後， $1 \mathrm{ml} 01 \mathrm{~N}$ $\mathrm{NaOH}$ 加えて乳液とし，その1 白金耳を培地中 央においた群，(2)(1)の乳液 $1 \mathrm{ml}$ に $4 \mathrm{ml} の 0.1 \mathrm{~N}$ $\mathrm{NaOH}$ 加えて希哷し，その0.05 mlを接種した 5 倍希䆏群, (3)(2)の $1 \mathrm{mlk} 4 \mathrm{ml}$ の0.1 N NaOHを加 えて希釈して，その0.05 mlを接種した25倍希釈

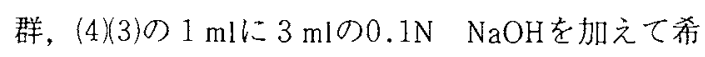
釈した $0.05 \mathrm{ml}$ を接種した100倍希䣋群を調整し $33^{\circ} \mathrm{C}$ で 3 月間培養した。

\section{結果}

ネズミライ菌增殖培地の水抽出液中に含まれ る匂い成分は活性炭に吸着した。滤別して水で 十分洗浄後, 乾燥した活性炭からのエ夕ノール 溶出液窒素気流下で濃縮すると, メズミライ 菌培養時に生成する特有の匂い成分が濃縮でき た。Fig. 1 はGC-MS分析の総イオンモニター から得られた濃縮液のガスクロマトグラムを示 す。主要な22ピークについてマススペクトルを
記録した。主要な4ピークのマススペクトルを Fig. 2に示した。データベース中に含まれる標 準化合物のマススペクトルとの類似度に基づく データ検索から化学構造が推定された化合物を Table 1 に示した。主要なピーク成分は17.02分に 溶出する methyl 3-hydroxy-hexanoate, 17.37分の phenylethanol, 25.92分のphenylacetic acidなどで ある。40.77分に溶出するピータ成分としては2 amino-phenylethanol, 1-phenyl-phenol どの可能 性は示崚されたものの, 同定には不十分な類似度 であった。

市販のphenylacetic acid及びそのメチルエステ ルとエチルエステルである methyl phenylacetate及 びethyl phenylacetateを混ぜた匂いは，ネズミラ 亿菌培養培地の水抽出液の濃縮液と極めてよく似 た匂いであった。

phenylacetic acidを含む小川卵黄培地でネズミ ライ菌の初代分離培養を接種菌の濃度を変えて 行ったが, phenylacetic acidがネズミライ菌の初 代分離培養を阻害する傾向は見られたものの，培 養の促進活性は全く観測されなかった。

\section{考察}

長期にわたるネズミライ菌のエネルギー代謝に 関する研究から著者の一人 (森) は，ネズミライ 菌が容易に培着できる他の抗酸菌とは異なる代謝 系を有すると考え，ネズミライ菌が培養時に呈す る特有の匂い成分に注目していた。 phenylethanol は酵母発醉を利用する酒類や醬油，味唄などに大 量に含まれているので， ネズミライ菌もアミノ 酸発酵に類する代謝系でエネルギーを産生してい る可能性がある。容易に培養できる他の抗酸菌に はphenylacetic acid臭を産生する菌株は見いたさ れていない。つまり phenylacetic acidを産生する のがネズミライ菌の特徵であって，ネズミライ菌 の特殊なチトクローム系 ${ }^{2)}$ とエネルギー産生系 ${ }^{3)}$ とに関連があると推察している。今後, pheny. lacetic acid産生に関連するネズミライ菌代謝に関 する詳細な研究が必要である。

活性炭を利用した匂い成分の処理法と培地の影 響もあるのであろうが，他の微生物に比ベベンゼ ン環を含む化合物が量, 種類共に著しく多いこと がネズミライ菌代謝産物の大きな特徵といえる。 
なお 40.78 分に溶出するピークは全体の $43 \%$ に及 ぶ念有量であるが，ピーク形状などから真の包い 成分と言うより二次的な生成物の可能性が強い。

phenylethanolやphenylacetic acidのような成分 は植物や微生物の最終代謝産物として体内に蓄積 されるもので，特別の成長促進因子的な意義や活 性はないと思われるが，その生成過程が特殊で興 味深いものがある。将来，ネズミライ菌のチトク ローム系とエネルギー産生系が似ているライ菌4 が培養できたとき，ライ菌が果たしてphenylacetic acidを産生するか否かは興味深い問題である。

\section{文献}

1）新版醸造成分一覧，（財）日本䁔造協会， 1977.

2) Mori, T., Kohsaka, K. and Dohme, K. Termin al electron transport system of $M$. lepraemurium. Int. J. Lepr. 39, (1971) 813-828.

3) Mori, T., Kohsaka, K. and Tanaka, Y. Tri. carboxylic acid cycle in $M$. lepraemurium. Int. J. Lepr. 39, (1971) 796-812.

4) Mori, T., Miyata, Y., Kohsaka, K. and Makino, M. Respiration in Mycobacterium lep. raemurium. Int. J. Lepr. 53, (1985) 600-609.
Table 1 Prospective compounds of odor component in cultivation of M. lepraemurium

\begin{tabular}{|c|c|c|c|}
\hline peak No & $\begin{array}{l}\text { retention } \\
\text { time (min) }\end{array}$ & $\operatorname{area}(\%)$ & name of compounds \\
\hline 1 & 12. 66 & 0.33 & $\begin{array}{l}\text { methyl } 2- \\
\text { methylbutanoate }\end{array}$ \\
\hline 2 & 14. 62 & 0. 26 & $\mathrm{~m} / \mathrm{z} 438410157154$ \\
\hline 3 & 15. 12 & o. 63 & methyl phenylacetate \\
\hline 4 & 15. 50 & 1. 08 & ethyl phenylacetate \\
\hline 5 & 16. 80 & 0. 71 & benzyl alcohol \\
\hline 6 & 17. 02 & 5. 04 & $\begin{array}{l}\text { methyl } 3 \text {-hydroxy- } \\
\text { hexanoate }\end{array}$ \\
\hline 7 & 17. 37 & 10. 17 & phenlyethanol \\
\hline 8 & 17. 55 & 0.28 & $\begin{array}{l}\text { 3-methyl- } \\
\text { phenylethanol }\end{array}$ \\
\hline 9 & 18. 51 & 0.77 & phenol \\
\hline 10 & 18. 93 & 2. 30 & $\begin{array}{l}\text { 1. 5-heptadiene- } \\
\text { 3. 4-diol }\end{array}$ \\
\hline 11 & 22. 57 & 2. 16 & 1, 2, 3-propanetriol \\
\hline 12 & 22. 63 & 1. 42 & $\begin{array}{l}\text { 4-methoxy-6-methyl } \\
-2 \mathrm{H} \text {-pyran } \\
-2 \text {-one }\end{array}$ \\
\hline 13 & 23. 91 & 3. 95 & benzoic acid \\
\hline 14 & 25.24 & 1. 00 & $\mathrm{~m} / \mathrm{z} 95124544286$ \\
\hline 15 & 25. 92 & 8. 65 & phenylacetic acid \\
\hline 16 & 27. 94 & 2. 10 & $\mathrm{~m} / \mathrm{z} 875539140122$ \\
\hline 17 & 28. 93 & 4. 37 & $\begin{array}{l}\text { dibutyl } 1,2- \\
\text { phenyldicarboxylate }\end{array}$ \\
\hline 18 & 30.70 & 1. 19 & $\begin{array}{l}\mathrm{m} / \mathrm{z} 1057751136 \\
109 ?\end{array}$ \\
\hline 19 & 32. 44 & 5. 05 & $\begin{array}{l}\mathrm{m} / \mathrm{z} 112144140172 \\
84\end{array}$ \\
\hline 20 & 34. 79 & 2. 07 & $\begin{array}{l}\text { methyl } 4 \text {-hydroxy- } \\
\text { phenyacetate }\end{array}$ \\
\hline 21 & 35.62 & 3. 33 & hexadecanoic acid \\
\hline 22 & 40.78 & 43. 04 & $\mathrm{~m} / \mathrm{z} 107771385191$ \\
\hline
\end{tabular}

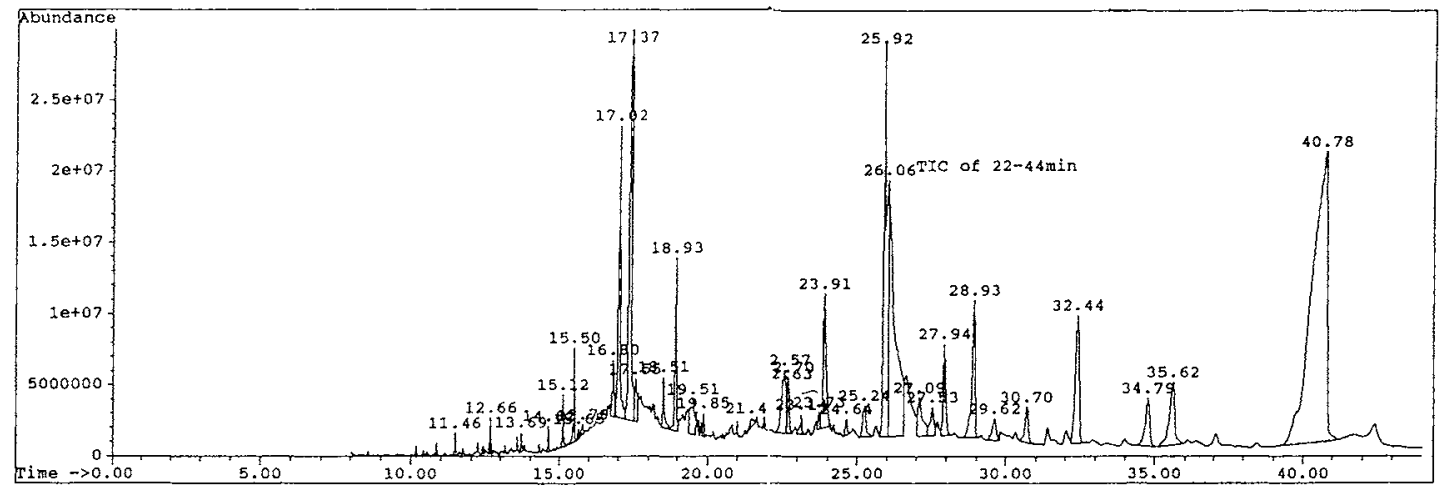

Fig. 1 Gas-chromatography of volatile components in metabolites in $M$. lepraemurium 


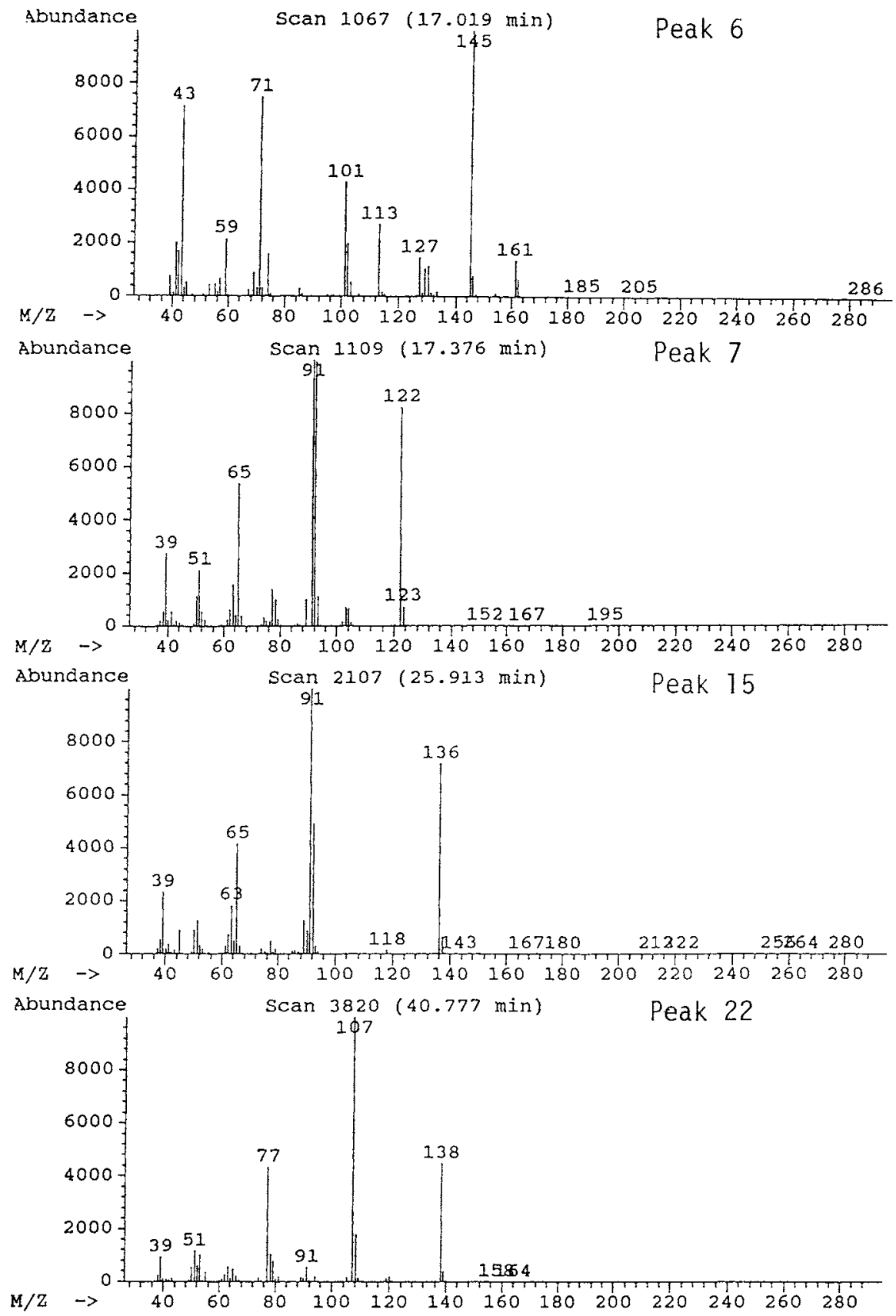

Fig. 2 Mass-spectrums of main four peaks 